Article

\title{
Roma Children and Young People in Bulgaria: Patterns of Risk and Effective Protection in Relation to Child Sexual Exploitation
}

\author{
Kate D’Arcy * and Isabelle Brodie \\ Department of Applied Social Studies, University of Bedfordshire, Bedfordshire, LU1 3JU, UK; \\ E-Mails: kate.d'arcy@beds.ac.uk (K.D.), isabelle.brodie@beds.ac.uk (I.B.) \\ * Corresponding author
}

Submitted: 17 January 2015 | In Revised Form: 15 April 2015 | Accepted: 4 May 2015 |

Published: 7 July 2015

\begin{abstract}
This article examines patterns of risk regarding child sexual exploitation (CSE). There is specific focus on those living in alternative care, child sexual exploitation and trafficking among Roma communities in Bulgaria and the UK. Data is drawn from a desk-based literature review and partnership work with Bulgarian and British academics and practitioners to explore the issues in both countries. Although there is limited statistical data on CSE and children in care across Europe and the risk-factors for Roma children and young people are still not being fully recognised, we can draw on what is known in Bulgaria to inform practice in the UK with emerging Roma communities. Research on CSE more generally can also inform awareness of risk factors particularly around care systems. Comparative information about what is known in the UK and Bulgaria is considered in order to make some recommendations for international prevention, protection efforts, and prosecution strategies for the future.
\end{abstract}

\section{Keywords}

child sexual exploitation; institutional care; risk; Roma; social inclusion

\section{Issue}

This article is part of a regular issue of Social Inclusion, edited by Professor Ulf R. Hedetoft (University of Copenhagen, Denmark).

(C) 2015 by the author; licensee Cogitatio (Lisbon, Portugal). This article is licensed under a Creative Commons Attribution 4.0 International License (CC BY).

\section{Introduction}

There are ten to twelve million Roma living in Europe. There is extensive evidence attesting to the poverty and discrimination experienced by Roma in all European countries, and a high level of concern at the movement of Roma into different parts of Europe, reflected in negative media coverage and public attitudes. The socio-economic disadvantage experienced by the Roma community has particular implications for the safety and well-being of children and young people, and this has become increasingly apparent in relation to the issue of Child Sexual Exploitation (CSE). This is an issue which has attracted attention at European policy level since the early 1990s, when the Palermo Protocol, aimed at preventing, suppressing and punishing trafficking in persons, including trafficking for the purposes of sexual exploitation, was issued.

The Council of Europe (2007, Article 18) defines Child Sexual Exploitation as:

engaging in sexual activities with a child where use is made of coercion, force or threats; or abuse is made of a recognised position of trust, authority or influence over the child, including within the family; or abuse is made of a particularly vulnerable situation of the child, notably because of a mental or physical disability or a situation of dependence.

There are major difficulties with the reliability of data, 
but the Council of Europe (2012) estimates that among every five children in Europe one will be a victim of CSE. Child Sexual Exploitation can be conceptualised as part of the spectrum of child abuse, and can take multiple forms, which range from grooming by an individual to more organised forms of exploitation, which may incorporate the exploitation of groups of young people and may include the trafficking and movement of young people both within and between different nation states (Department for Education, 2011; ECPAT UK, 2011). Poverty and different forms of socioeconomic disadvantage place children and young people at greater risk of child sexual exploitation, and also contributes to the children affected being marginalised or "hidden" from public view (Pearce, 2009). Those who are living in alternative care or missing from care provision are at increased risk of CSE, though care should be taken in assuming the nature of causal connections between living in alternative care and being exploited-so, for example, the exploitation may precede entry to care and continue during the placement (Brodie, Melrose, Pearce, \& Warrington, 2011). These risks are usually related to wider patterns of disadvantage, such as a lack of adult advocacy and lack of protective structures, for example limited educational opportunities. Although international data is even more limited still, the existing evidence suggests that children living in alternative care internationally are also at heightened risk of this form of maltreatment (SOS Children's Villages International \& University of Bedfordshire, 2014).

The focus of this paper is to examine the risk factors associated specifically with the Roma community and the increased likelihood that Roma children and young people will experience trafficking and alternative care, usually in the form of institutions. Roma communities are among the most marginalised communities and observing their risk-factors will inform new learning which can be applied to other vulnerable groups of children and young people. Research based information from Bulgaria and the UK will also be utilised to identify new strategies to reduce abuse and Roma's communities' marginalisation as this plays a part in their vulnerability to CSE in the UK and Bulgaria.

Using such comparative information is not, of course, without difficulty. Bulgaria and the UK represent very different social, political and economic contexts with important historical differences in their policy and practice approaches to the care of children separated from their families. International comparison of care systems is notoriously difficult (Thoburn, 2007) in the context of variations in definition, resulting in differences in data collection, structural arrangements such as the balance between foster and residential care, and the relationship between child welfare policy and the type of welfare state (EspingAnderson, 1990). At the same time, researchers have also drawn attention to the value of such an approach in the field of child welfare, especially in a political context where international protocols play a significant role in driving national policy. Additionally, there is an ongoing need to recognise child sexual exploitation as a transnational and trans-European phenomenon, and that the prevention of such exploitation requires shared learning and action.

\section{Patterns of Risk: Vulnerabilities to Child Sexual Exploitation}

Roma are among the poorest communities in Europe. In Bulgaria, Roma have poor access to healthcare, education and employment and are consequently trapped in a cycle of poverty. "Infant mortality is high, family planning is often too expensive and abandonment is common. Unemployment stands at $80-85 \%$ and less than $1 \%$ of Roma children complete a secondary education" (The Trussell Trust, 2015).

In the UK the Roma were described in 2009 as "hidden communities" (European Dialogue, 2009) as there are many unidentified Roma accessing schools, health care and welfare and work systems. This is because they have not ascribed by choice or simply have no contact with services, and have therefore gone unnoticed. Roma from Central Eastern Europe initially arrived in the UK as asylum seekers and today as EU citizens. Feteke (2013) suggests that Roma tend to settle in urban multi-ethnic areas, with the largest populations in the North West and London, although there are significant populations in Yorkshire and the Humber, East Midlands and West Midlands. There is very little data on the total Roma population, although numbers are estimated to be around 200,000 (Brown, Scullion, \& Martin, 2013). Despite the heightened attention to CSE in England (Jay, 2015), data on CSE among the Roma population is currently unreported, although anecdotal reports from professionals suggest that the number of children in care is rising. In Rotherham Roma children are three times more likely to end up in institutional care and foster care (Cox, 2013). Yet the reasons for entering care are in part about cultural divides that relate to different legal and social expectations e.g. poor school attendance, chastising children and a lack of boundaries and children's involvements in petty crime such as street begging.

These cultural divides are apparent in the UK and in Bulgaria and it is clear that social services in both countries need to know more about Roma culture and their risk factors in relation to CSE in order to make appropriate decisions and work with the community to prevent Roma being further criminalised and having their children placed into care. While the experience of Ro$\mathrm{ma}$ is distinct in view of the entrenched and widespread nature of the discrimination experienced, it is also possible to conceptualise the Roma experience as 
reflecting wider structural patterns relating to care. Families who experience social work intervention are likely to be experiencing considerable stress and will be known to social services, but do not receive the help they need either to prevent entry to care, or a timely decision for the child to enter care (Masson et al., 2008). Thus although this article focuses on Roma particularly, the key messages are relevant to other vulnerable groups.

The State Agency for Child Protection (2013) in Bulgaria shows that numbers of children who experience violence is rising, which could be evidence of better recognition and reporting of abuse. Petrova-Dimitrova (2005) categorised those children most at risk of abuse in Bulgaria:

- Children living on the streets;

- Children in institutions, the risk is here from children to children and from staff;

- Children in poor and marginalised families, especially from ethnic minorities. Roma girls aged 1017 are at very high risk as they are victims of theft or sale for trafficking and prostitution;

- Young people (12-15) who have problematic relations with parents and adults. They disengage from education and consequently are at high risk of sexual abuse and prostitution.

Roma families would be represented in all four categories due to wider social exclusion towards their community. Because Roma community are not socially supported or included they are often living in poverty and find the costs of bringing up their children hard to bear. Research suggests that many Roma families give up their children to institutions due to wider welfare issues, as discussed in the following section.

\section{Institutional Care in Bulgaria and the Roma Community}

There are links between institutionalisation and CSE as young people in institutions are at risk from adults and peers who may target residential units for the purposes of abuse and staff who fail to notice or report abuse. Children and young people entering care systems often have complex histories of abuse and disadvantage, and this can make them more vulnerable both to individual abusers and organised groups. Moreover, when institutions put their own needs before children's, abusive behaviours can become normalised, leading to sexual abuse (NCA, 2013). Roma children and young people are particularly over represented in the institutional care system. Researchers (Bulgarian Helsinki Committee, 2011) visited 15 Bulgarian children's institutions in which a total of 809 children lived, of whom 510 were
Roma ${ }^{1}$. The main reasons for Roma children's institutionalisation appear to be family poverty and low educational achievement which can lead to the migration of the parents in search of employment and in turn the abandonment of children. Inadequate housing conditions, a lack of community-based services for Roma children and families and lack of effective family planning among Roma women also raises the number entering care. Once in care, Roma children's chances of being adopted or placed into foster care are also reduced due to widespread racial prejudice (Eurochild, 2012b). Prevention is complex as there are wider welfare issues at stake and a multitude of issues to be addressed and abandonment and trafficking are two such issues, which are discussed next.

\section{Abandonment and Care Systems}

The Social Assistance Agency (2009) reported 3,597 cases of abandonment of children in Bulgaria. Roma children are at higher risk of being abandoned or left in institutions because their parents live in poverty, are ill, imprisoned or looking for work away from where they live. Social workers summarised the high-risk characteristics of Roma women who leave their children in institutions voluntarily or whose children are protected from risky environments:

- Women who left school early, married early and had their first child between 13-16 years of age and have many children by the time they are 30;

- Women separated from their original husbands, who live in poverty as they depend on poor paid work (collecting garbage, ironing and begging);

- Mothers who migrate in search of income (occupation is often unknown and may well be prostitution) and leave their children with parents, who become ill and the children enter care.

Once these children enter institutions mothers lose contact with their children even though they keep parental rights (Bulgarian Helsinki Committee, 2011). Children often run away from state care and many are Roma. Any child who lives on the street and is not in education is particularly vulnerable to CSE and trafficking, and they are often involved in prostitution and drug-abuse.

Again, the Roma and Bulgarian experience should be considered in the context of international trends in residential care. Children who are in "alternative care" are those who are not living with or being cared for by their biological parents. Their situations are often complex and the Convention on the Rights of the Child

\footnotetext{
${ }^{1}$ These issues are well known but there are no official statistics because institutional data does not monitor children's ethnic identity.
} 
(UNCRC, 1989) recognises they may need additional protection from harm. Article 20 describes alternative care as including "inter alia, foster placement, kafala of Islamic law, adoption or if necessary placement in suitable institutions for the care of children". In the Bulgarian and UK contexts, institutional or family foster care are the main placements for Roma children and therefore the focus of this article.

Institutional care describes residential settings where children and young people are cared for by adults employed for this purpose. Foster care is a form of accommodation for children who are cared for in a smaller, family based setting by one or two carers. Accurate data on those living in institutions is hard to obtain. It has been estimated that more than 2 million children are in institutional care around the world, with more than 800,000 in Central and Eastern Europe and the Commonwealth of Independent States (CEE/CIS). This global estimate is likely to be severely underestimated due to under-reporting and lack of reliable data. Many institutions are unregistered and many countries do not regularly collect and report data on children in institutional care (UNICEF, 2010).

International evidence attests to the degree of marginalisation and stigma associated with institutional care (Bazalgette, 2014; Morgan, 2007). Bilson and Cox (2007) suggest that this is in part due to the continuing "rescue mentality" or belief that children are better off away from their own families. Fox-Harding (1997) has shown that this mentality has persisted into the $21^{\text {st }}$ century in the UK even though foster care is now preferable to institutions. In Bulgaria institutions have historically been relied on as a safety net for social workers, and treated as a long-term solution rather than one which seeks to reintegrate children with their families. The historic and economic reasons such as the breakup of the USSR and a lack of policy directives regarding alternative placements also resulted in the promotion of institutional care. Yet large institutions have a negative impact on children's physical and cognitive development, emotional security, attachment, cultural and personal identity (Browne, 2005; Eurochild, 2012a). Hanlon (2007) outlines the different forms of inequality to which children living in care are subject, including inequalities of resource, power and representation and love and care as well as the more measurable disadvantages in respect to education, employment and other future life outcomes. As shown above, these inequalities are compounded for the already disadvantaged Roma community. At the same time, even in countries where the use of institutions has diminished, residential care continues to represent an option for a minority, and does not seem likely to disappear (Cliffe \& Berridge, 1991; Rahilly \& Hendry, 2014).

Institutional care for all groups gradually fell out of favour during the $20^{\text {th }}$ century, and this trend continues internationally. Throughout Europe, deinstitutionalisa- tion is a political priority as there have been central concerns about the quality of care and the effect of large institutional care on children's development. Institutional care is also expensive. The de-institutionalisation agenda focussed on replacing large institutions with community-based services which include foster care arrangements where children are placed in smaller, care environments where they can develop attachment through closer relationships with key adults. Yet progress is slow, for example the Commissioner for Human Rights Strasbourg reported that Romania needs to show a stronger commitment to effectively protecting the human rights of persons with disabilities, children and Roma as they are isolated from society in a growing number of institutions, where they often face inhumane and degrading treatment and, in some cases, deliberate abuse (Council of Europe, 2014). Often this is related to a lack of welfare infrastructure. A foster care pilot in Albania, for example, found that it was possible to find and support kin foster placements, including foster care for Roma children. However, when funding was withdrawn, the lack of capacity in the welfare system meant that support for these families was no longer available (Stevens, Connolly, \& Milligan, 2013).

\section{Trafficking}

The movement and trafficking of children and young people for the purposes of child sexual exploitation has become an issue of international significance and has been addressed through the UN's Protocol to Prevent, Suppress and Punish Trafficking in Persons, especially Women and Children (2000). The protocol's definition of trafficking lists prostitution and other forms of sexual exploitation alongside forced labour, slavery or similar practices, and the removal of organs. Research in the UK has found evidence of sexual exploitation involving the movement of children and young people within the country and from outside (see, for example, Marie and Skidmore (2007), Pearce, Hynes and Bovarnick (2009), and Scotland's Commissioner for Children and Young People and Centre for Rural Childhood, Perth College UHI (2011)).

There is growing awareness of the issue of trafficking in the UK, but while there is some consensus that this is a growing phenomenon there is ongoing debate regarding the scale and nature of the issue (Rigby, Malloch, \& Hamilton-Smith, 2012). Within this debate there has been considerable concern at the numbers of young people who have been or at risk of trafficking and who are placed in residential care, but then go missing (ECPAT UK, 2011; Marie \& Skidmore, 2007; Scotland's Commissioner for Children and Young People, \& Centre for Rural Childhood, Perth College UHI, 2011). In a review of young people in one local authority area who had been trafficked into the UK, over half of the 60 cases went missing within a week of arrival 
(Harris \& Robinson, 2007). This may be the result of abduction-and further trafficking within the UK-or the young person may run away.

Existing evidence emphasises the complexity of the processes associated with trafficking, and that multiple forms of abuse may have taken place. It is therefore important that the problem of trafficking is not reduced to one of sexual exploitation alone. Young people are likely to be very fearful and therefore unwilling to disclose what has happened to them. Young people report encountering barriers including language, suspicion and criminalisation (Pearce et al., 2009). Within residential care, evidence suggests that staff do not have sufficient awareness or training regarding trafficking, and that resources are frequently not available to ensure the high level of supervision and specialist intervention required.

More generally, it is recognised that practice in this area is complex, and that further work to evaluate the effectiveness of different interventions is required (Rigby et al., 2012). However, there is agreement that the welfare of the child or young person must be paramount, that they should be helped to make their views known and given information about what is happening to them. Children and young people who are trafficked should be recognised as victims of abuse, and the trauma of their experiences should be recognised. In these cases the provision of safe accommodation is crucial, but is too often unavailable and children and young people continue to be placed at risk (ECPAT UK, 2011; Pearce et al., 2009; Shuker, 2013).

In Bulgaria, there is limited information about those missing from care and the links to trafficking. Police and NGOs reported that most victims of trafficking are identified abroad, following a police raid or with NGOs working proactively with those in protection/sex work (Roma Rights Centre, 2011). Bulgaria is one of the few countries in Europe that have a national referral mechanism for victims of trafficking.

Still, according to anti-trafficking practitioners there has not yet been a case where parents who have trafficked or exploited their own children and have had their parental rights taken away. Often after 6 months in a crisis centre, children are returned home where they continue to be exploited. It is very difficult for children to testify against their own relatives. The Centre for the Study of Democracy suggest that at policy level child victims are addressed but there is a lack of understanding of the interconnectedness between different aspects of child trafficking. Tensions within trafficking reflect those in social care and CSE as there is conflict between the repressive and protective function of the state; a child can be a victim and an offender at the same time (Centre for the Study of Democracy, 2012, p. 22).

Roma constitute a disproportionally high number of persons trafficked because of poverty and growing up in state care. Within Bulgaria women and children are most often induced into prostitution in the towns on the Black Sea coast and border areas. Countries of destination for Bulgarian trafficking victims are the Netherlands, Belgium, France, Austria, Italy, Germany, the United States, the Czech Republic, Finland, Greece, Spain, Norway, Poland, Portugal, Switzerland, Turkey, Cyprus and Macedonia. Roma women and children represent $15-80 \%$ of all trafficking victims. Some Bulgarian children are induced into street begging and petty theft within Bulgaria, Greece, Italy and the UK (Center for the Study of Democracy, 2012). Traditional stereotypes regarding the mobility of the Roma community are also problematic in respect to the prevention and detection of child sexual exploitation and other forms of abuse. For example, in the context of trafficking it is important to recognise that migration refers to the voluntary movement of people which leads to improvements in life, as opposed to trafficking which is a form of modern day slavery, involving enforced, not voluntary movement (ERRC, 2011).

These findings reinforce the need for appropriate cultural awareness raising and multi-agency working. Pro-active and collaborative working to prevent CSE and trafficking is the overarching point made throughout the literature. Joined up international strategies are needed in identifying, supporting and reintegration of victims. What we also learn from these findings is that wider social exclusion affects Roma's welfare and this has consequences for their children's risk factors to CSE and routes into care and in the family setting. Subjected to poverty, violence and unequal treatment by services which should support their needs, Roma children are severely disadvantaged.

\section{Effective Protection}

Increasingly there is international movement of citizens and in order to facilitate appropriate care and protection of children professionals need to work with families and communities. The UN Convention on the Rights of the Child, article 34 states that all children should be protected from sexual exploitation and sexual abuse. The UN article 20 also states that children in alternative care must be protected. This process is not simple. The specific issues in Bulgaria are different to those in the UK, but some key elements regarding risk factors are similar and can be useful as a focus for awareness raising and prevention work.

\subsection{Links between Care and CSE}

In regards to child protection systems there are several issues are worthy of consideration at this point. It is clear that managing and dealing with child abuse is complex due to a combination of factors at different levels.

In Bulgaria, the Child Protection Act was adopted in 
2001 and systems for identifying, recording and, consequently, addressing different forms of abuse are still developing. The basic principles of child protection in Bulgaria relate to those in other European countries, including the UK. In the UK safeguarding is a Local Authority's responsibility and the Local Safeguarding Children's Board (LSCB) is the key method for ensuring that relevant organisations in each local area are working together to safeguard children, they monitor and evaluate practice and review any deaths of children in their areas. At grassroots, delivery levels there are also differences in practice.

In Bulgaria there is no threshold system, or a means to match different kinds of cases with different services. This means that the average social work can hold a caseload over a hundred, compared to UK workers who typically have around a quarter of that number (Community Care, 2013). Carrying such workloads brings real challenges in prioritising work, especially preventative strategies. In the UK there are thresholds in place, but there are still challenges related to the focus of work. Evaluations of safeguarding board arrangements in the UK found that professionals were committed to safeguarding as a shared responsibility, but tensions did exist as to whether they should embrace wider safeguarding issues or a narrower focus on protecting children from harm (France, Munro, \& Waring, 2010).

Increasing resource issues means that raising awareness of the nature of CSE is an important prevention strategy among wider professional body, families and communities. Pro-active, well-coordinated partnership approaches are vital in preventing child sexual exploitation. Where organisations such as the police, children's services and NGOs work together to identify and address child sexual exploitation, a significant number of cases have come to light. On the other hand where agencies do not routinely engage victims and collect data, few cases appear (CEOP, 2011). Agencies which do not proactively look for child exploitation will as a result not find it (CEOP, 2011). Better data collection on the ethnicity of victims and those at risk of CSE and who are in care and missing from care would help build up a more informed picture of the issues in Bulgaria and UK, and other European countries and would allow agencies to work together on evidenced-based action plans. Training and support for a wide range of practitioners as well as awareness raising among Roma communities in both Bulgaria and the UK is needed to help professionals and communities alike to recognise and report CSE. Community awareness would need to be culturally appropriate and would be best delivered by a community champion model which has proved to be effective in raising awareness of sensitive issues in different communities (Bostock, 2015).

Research from other countries, but especially the UK, has highlighted that factors which may increase vulnerability to CSE-prior abuse, neglect, family dysfunction, educational difficulties, substance misuse and a history of running away-are also factors that are present in the histories of young people entering residential care. Again, these factors do not determine that sexual exploitation will take place, but they may mean that the young person is more vulnerable to sexual exploitation and the relationship or material goods that may be offered. It is also increasingly evident that children who have experienced multiple difficulties and have complex life histories are more likely to be defined as "problematic" and as bringing problems on themselves by "placing themselves at risk". This culture of blame makes it difficult for young people to find help and to escape exploitation. This issue is likely to be magnified in the case of Roma children and young people, whose families will often have had negative and discriminatory experience of wider society and the authorities.

In Bulgaria there is relatively high tolerance towards sexual abuse of girls over 14 . Girls of 14 are living with men of 40 but this will not be recorded as child abuse if parents approve. Where the girls are Roma, no one can make institutions take action (PetrovaDimitrova, 2005). Child marriage represents the most prevalent form of sexual abuse and exploitation of children, especially girls. While child marriage is criminalised in Bulgaria for children under 16, crimes related to marriage are not identified and prosecuted. Forced marriage continues to be practiced among certain Roma communities. A common reason for trafficking of young Roma women in Bulgaria is that they marry too early, from the age of 14) after the husband "steals the girl" and after a few years of marriage these girls escape and are then vulnerable to trafficking and/or prostitution. Raising awareness to change public and professional perceptions around blame, consent and legislation is therefore necessary to prevent CSE.

In the UK, media reports highlight institutional abuse cases, however residential care can be the service responding to prior experience of sexual exploitation, rather than being the source of the problem. If residential care is a turning point in respect of a young person's vulnerability to sexual exploitation then staff must feel adequately informed and confident in supporting these needs. For those in care, research suggests that there is value in linking residential units with a wider network of services for young people (youth work services, advocacy learning mentors) as this maximises young people's opportunities to form positive relationships with professionals (Brodie et al., 2011). Lessons learnt in the UK and elsewhere suggest that it is also important to consider the contact arrangements between children in care and existing parents, so that placements might be short-term and children remain in contact with their families, and this could be applied to Bulgarian contexts where children are left by parents in 
institutions long-term even though they still have parental responsibility. The geographical distance is relevant here as the closer the care setting to the family the easier contact can be and this can also reduce the risk factors associated with CSE and trafficking.

\subsection{Wider Welfare Issues}

Discrimination and cultural expectation of Roma affects the support they receive and consequently the care of their children, even though the UNCRC states that due regard shall be paid to the desirability of continuity in a child's upbringing and to the child's ethnic, religious, cultural and linguistic background (Celcis, 2012), Roma children are still abandoned to institutions where their cultural needs and long-term social inclusion is severely restricted. More generally, it is clear that children and young people living in care and experiencing poverty as family dysfunction are especially vulnerable. Children living in dysfunctional family situations are vulnerable due to wider welfare issues such as poverty and unemployment which can affect their entire community's social inclusion. Some families do resort to trafficking their own children or involving them in prostitution purely as a survival strategy. Thus any preventative work must consider wider social welfare issues of high-risk families as well as appropriate support for victims. Prevention might include family planning, health and welfare support, access and retention in education and offering training and employment opportunities for particularly vulnerable groups such as Roma. Prevention might also include awareness raising about education and care to help new migrant Roma communities understand legal expectations regarding child protection and prevent child neglect, exploitation and children's entry into care. Such an approach needs to be in partnership with the community, ensuring that awareness raising activities are planned and delivered together to develop meaningful and respectful resources and relationships which can ultimately prevent child abuse and exploitation and address social exclusion.

\section{Conclusion}

The focus of this paper has been to examine the CSE risk factors associated specifically on the Roma community in the hope that this will inform new learning which can be applied to other vulnerable groups of children and young people. The aim is also that this new learning would result in action to work preventative together to reduce the occurrence of CSE. Child protection procedures and responsibilities need to be revised continuously and training needs to be available for all adults involved in the care of vulnerable young people to ensure they can spot the signs of CSE and know-how and who to report concerns to. Profes- sionals also need to understand and appreciate different cultural needs and the reality of discrimination upon Roma communities' lives to help advance their marginalised position in society. There are connections between being a child in care, or leaving care, and vulnerability to CSE and this article has offer a comparison of factors between two European countries. Effective multi-agency working at policy and grassroots levels is key to preventing CSE and entry into care and further international comparisons to develop new strategies would certainly enable lessons to be shared and prevention strategies to be applied more broadly in an international context.

\section{Conflict of Interests}

The author declares no conflict of interests.

\section{References}

Bazalgette, L. (2014). The views of looked after children and young people on the care system. In T. Rahilly \& E. Hendry (Eds), Promoting the wellbeing of children in care. London: NSPCC.

Bilson, A., \& Cox, P. (2007). Caring about poverty, alternatives to institutional care for children in poverty. Journal of Children and Poverty, 13(1), 37-55. doi:10.1080/10796120601171294

Bostock, L. (2015). Effective approaches to community awareness raising of child sexual exploitation: A review of the literature on raising awareness of sensitive social issues. Bedfordshire: University of Bedfordshire. Retrieved from http://www.beds.ac.uk/ intcent/publications

Brodie, I., Melrose, M., Pearce, J., \& Warrington, C. (2011). Providing safe and supported accommodation for young people who are in the care system and who are at risk of, or experiencing, sexual exploitation or trafficking for sexual exploitation. Luton: University of Bedfordshire. Retrieved from http://www.beds.ac.uk/iasr/publications

Brown, P., Scullion, L., \& Martin, P. (2013). Migrant Roma in the United Kingdom: Population size and experiences of local authorities and partners. Salford: University of Salford. Retrieved from http://www.salford.ac.uk/environment-lifesciences/about/environment-and-life-sciencesnews/study-finds-uk-has-200,000-roma-migrants

Browne, K. (2005). A European survey of the number and characteristics of children less than three years old in residential care at risk of harm. Adoption and Fostering, 29(4), 23-33.

Bulgarian Helsinki Committee. (2011). Roma children at risk in the child protection system in Bulgaria. Sofia: Bulgarian Helsinki Committee.

Centre for Excellence for Looked After Children in Scotland (Celcis). (2012). Moving forward: Implementing 
the guidelines for the alternative care of children. Glasgow The Centre for Excellence for Looked After Children in Scotland.

Center for the Study of Democracy. (2012). Assisting and reintegrating child victims of trafficking in Bulgaria: Legal, institutional and policy framework. Sophia: Center for the Study of Democracy.

CEOP. (2011). Making every child matter, everywhere, executive summary, CEOP thematic assessment. London: CEOP.

Cliffe, D., \& Berridge, D. (1991). Closing children's homes: An end to residential child care? London: National Children's Bureau.

Community Care. (2013). Half of social workers have seen colleague quit over caseloads. Retrieved from http://www.communitycare.co.uk/2012/07/17/half -of-social-workers-have-seen-colleague-quit-overcaseloads/\#.UnI-P9jTdn8

Council of Europe. (2007). Convention on the Protection of Children against Sexual Exploitation and Sexual Abuse, CETS No. 201, Article 18. Strasbourg: Council of Europe.

Council of Europe. (2014). Protecting children from sexual violence: A comprehensive approach. Retrieved from http://www.coe.int/t/dg3/children/ 1in5/WhatWeKnow/Publication_en.asp

Council of Europe. (2014). Retrieved from http://www. coe.int/en/web/portal/-/vulnerable-groups-require -better-protection-in-romania?inheritRedirect=true

Cox, S. (2013). Roma children in care, BBC Four programme Thursday $20^{\text {th }}$ Dec 2012. Retrieved from http://www.bbc.co.uk/programmes/b01pcsm9

Department for Education. (2011). Tackling sexual exploitation: Action plan. London: Department for Education.

ECPAT UK. (2011). On the safe side: Principles for the safe accommodation of child victims of trafficking. London: ECPAT UK.

Esping-Andersen, G. (1990). The three worlds of welfare capitalism. Princeton, NJ: Princeton University Press.

Eurochild. (2012a). De-institutionalisation and quality alternative care for children in Europe, lessons learned and the way forward. Working Paper. Italy: Eurochild.

Eurochild. (2012b). Speak up: Giving a voice to European children in vulnerable situation. Italy: Eurochild.

European Dialogue. (2009). The movement of Roma to new member states. Retrieved from http://equality .uk.com/Resources_files/movement_of_roma.pdf

European Roma Rights Centre (ERRC). (2011). Breaking the silence, Trafficking in Roma communities. Hungary: ERRC.

Feteke, L. (2013). No going back for the Roma. A review of the Migrant Roma in the UK research report. London: Institute for Race relations. Retrieved from http://www.irr.org.uk/news/no-going-back-for-the- roma

Fox-Harding, L. (1997). Perspectives in child care policy (2nd ed.). Longman: London.

France, A., Munro, E., \& Waring, A. (2010). The evaluation of arrangements for effective operation of the new local safeguarding boards in England. London, DCSF.

Hanlon, N. (2007). An equality perspective on residential child care. Scottish Journal of Residential Child Care, 6(1), 22-31.

Harris, J., \& Robinson, B. (2007). Tipping the lceberg: $A$ pan Sussex study of young people at risk of sexual exploitation and trafficking. Barkingside: Barnardo's.

Jay, A. (2015). Independent inquiry into child sexual exploitation in Rotherham (1997-2013). Rotherham: Rotherham Metropolitan Borough Council.

Marie, A., \& Skidmore, P. (2007). A summary report mapping the scale of internal trafficking in the UK based on a survey of Barnardo's anti-sexual exploitation and missing services. Barkingside: Barnardo's.

Masson, J., Pearce, J., Bader, K., Joyner, O., Marsden, J., \& Westlake, D. (2008). Care profiling study. MoJ Research Series 4/08. London: Ministry of Justice.

Morgan, R. (2007). Looked after in England: How children living away from home rate England's care. London: Commission for Social Care.

National Crime Agency (NCA). (2013). CEOP thematic assessment: The foundations of abuse, a thematic assessment of the risk of child sexual abuse by adults in institutions. London: NCA.

Pearce, J. J. (2009). Young people and sexual exploitation: "It's not hidden, you just aren't looking". Oxford: Routledge Falmer.

Pearce, J., Hynes, P., \& Bovarnick, S. (2009). Breaking the wall of silence: Practitioners' responses to trafficked children and young people. London: NSPCC.

Petrova-Dimitrova, N. (2005). Sexual abuse of children analysis of the situation in Bulgaria. Sophia: Independent research.

Rahilly, T, \& Hendry, E. (Eds.). (2014). Promoting the wellbeing of children in care. London: NSPCC.

Rigby, P., Malloch, M., \& Hamilton Smith, N. (2012). A report on child trafficking and care provision: Towards better survivor care. Scotland: University of Sterling.

Roma Rights Centre. (2011). Breaking the silence, trafficking in Romani communities. Retrieved from http://www.errc.org/cms/upload/file/breaking-thesilence-19-march-2011.pdf

Scotland's Commissioner for Children and Young People, \& Centre for Rural Childhood, Perth College UHI. (2011). Scotland: A safe place for child traffickers? A scoping study into the nature and extent of child trafficking in Scotland. Edinburgh: SCCYP.

Shuker, L. (2013). Evaluation of Barnardo's safe accommodation project for sexually exploited and trafficked young people. Ilford: Barnardo's. 
Social Assistance Agency. (2009). Annual report, European Commission. Brussels: European Commission.

SOS Children's Villages International, \& University of Bedfordshire. (2014). From a whisper to a shout: $A$ call to end violence against children in alternative care. Austria: SOS Children's Villages International.

State Agency for Child protection. (2013). Retrieved from http://sacp.government.bg/programi-dokladi/ dokladi

Stevens, I., Connolly, G., \& Milligan, I. (2013). Moving forward on residential care: Assessment of the foster care pilot in Albania. Glasgow: Celcis.

The Trussell Trust. (2015). Retrieved from http:// www.trusselltrust.org/roma-community
Thoburn, J. (2007). Globalisation and child welfare: Some lessons from a cross-national study of children in out-of-home care. Social work monographs, University of East Anglia. Norwich: University of East Anglia.

UNCRC. (1989). United Nations Convention on the Rights of Children: Summary. Retrieved from http://www. crae.org.uk/media/26693/UNCRC-CRAE-summary.pdf

UNICEF. (2014). Families not orphanages. New York: UNICEF.

United Nations. (2000). Protocol to suppress and punish trafficking in persons, especially women and children, supplementing the United Nationals Convention against transnational organised crime. Geneva: UN.

\section{About the Authors}

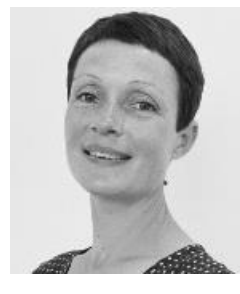

1.

\section{Dr. Kate D'Arcy}

Kate D’Arcy is Acting Principle Lecturer in Applied Social Sciences at the University of Bedfordshire. Having worked in education for many years, her practice has been mainly situated on the margins of education, supporting a variety of vulnerable and often disengaged young people. Kate worked as part of a Traveller Education service as a youth \& community development coordinator for many years to improve educational access and achievement for Gypsy, Roma and Traveller pupils and their families.

\section{Dr. Isabelle Brodie}

Isabelle Brodie is Senior Lecturer in the Department of Education Studies at the University of Bedfordshire. She has worked as a researcher for some 20 years in areas relating to child welfare. She has also undertaken or participated in a range of projects relating to child sexual exploitation. These include a scoping study for the Scottish Government, research relating to the relationship between care and exploitation for the NSPCC, and work on gangs and child sexual exploitation for the Office of the Children's Commissioner in England. 